\title{
Cost-Effectiveness of Pazopanib Versus Sunitinib for Renal Cancer in the United States
}

Thomas E. Delea, MSIA; Jordan AmdahI, BS; Jose Diaz, MD, MSc; Hamid Reza Nakhaipour, MD, MSc, PhD; and Michelle D. Hackshaw, BScPharm, MSHS, PhD

\begin{abstract}
BACKGROUND: Current first-line treatments for metastatic renal cell carcinoma (mRCC) include the multityrosine kinase inhibitors pazopanib and sunitinib. Both agents had similar progression-free survival (PFS) and overall survival (OS) in the COMPARZ trial (Comparing the Efficacy, Safety and Tolerability of Pazopanib versus Sunitinib); however, the adverse event profiles of the 2 agents are different. In the PISCES trial (Patient Preference Study of Pazopanib versus Sunitinib in Advanced or Metastatic Kidney Cancer), patients and physicians preferred pazopanib primarily because it offered better health-related quality of life (HRQOL) and caused less fatigue.
\end{abstract}

OBJECTIVE: To compare the cost-effectiveness of pazopanib versus sunitinib from a U.S. health care system perspective in the first-line treatment of patients with $\mathrm{BRCC}$.

METHODS: A partitioned-survival analysis model with 3 health states (preprogression, postprogression, and dead), data from 2 randomized controlled trials of pazopanib versus sunitinib (COMPARZ and PISCES), and secondary sources were used to calculate the incremental cost per quality-adjusted life-year (QALY) gained for pazopanib versus sunitinib. A time horizon of 37.5 months was used in the base case, consistent with the duration of follow-up used in the COMPARZ trial. The proportion of patients in each health state over time was based on Kaplan-Meier survival distributions for PFS and OS from the COMPARZ trial. Utility values were obtained from the PISCES trial. Costs were based on medical resource utilization data from the COMPARZ trial and unit costs from secondary sources. Probabilistic sensitivity analyses and deterministic sensitivity analyses were conducted.

RESULTS: In the base case, pazopanib was estimated to provide more QALYs at a lower cost compared with sunitinib (pazopanib dominant). In probabilistic sensitivity analyses, pazopanib was projected to be dominant in $69 \%$ of the simulations. The probability that pazopanib was more cost-effective than sunitinib was $\geq 90 \%$ for threshold values of costeffectiveness between the range of $\$ 10,000-\$ 160,000$ per QALY gained. In deterministic sensitivity analyses, pazopanib was dominant in all scenarios examined.

CONCLUSION: Results of this study suggest that pazopanib is cost-effective compared with sunitinib as the first-line treatment of patients with $\mathrm{mRCC}$ in the United States.

J Manag Care Pharm. 2015;21(1):46-54

Copyright $\odot 2015$, Academy of Managed Care Pharmacy. All rights reserved.

\section{What is already known about this subject}

Pazopanib has been directly compared with sunitinib in 2 phase III randomized trials in patients with advanced/metastatic renal cell carcinoma (mRCC) who had not received prior treatment. Results of the COMPARZ trial (Comparing the Efficacy, Safety and Tolerability of Pazopanib versus Sunitinib), a randomized, open-label, parallel-group study, demonstrated the noninferiority of pazopanib compared with sunitinib with regard to progression-free survival.

The PISCES trial (Patient Preference Study of Pazopanib versus Sunitinib in Advanced or Metastatic Kidney Cancer), a doubleblind, crossover study that assessed patients' preferences for pazopanib versus sunitinib, showed that both patients and physicians preferred pazopanib to sunitinib primarily because it offered better health-related quality of life and caused less fatigue.

\section{What this study adds}

This study compares the incremental cost-effectiveness of pazopanib versus sunitinib from a U.S. health care perspective.

Results of this study suggest that pazopanib is cost-effective compared with sunitinib as the first-line treatment of patients with mRCC in the United States.

$\mathrm{R}$ enal cell carcinoma (RCC) represents approximately $85 \%$ of all renal cancers. ${ }^{1}$ In the United States, an estimated 63,920 individuals are expected to be diagnosed with cancer of the kidney and renal pelvis in 2014, and an estimated 13,680 are projected to die from this cancer. ${ }^{2}$ Approximately $17 \%$ of patients with RCC present with metastases at diagnosis and have a 5 -year relative survival of only $12.3 \%$.

RCC does not respond well to chemotherapy. Immunotherapy such as interferon-alpha (IFN- $\alpha$ ) has the twin drawbacks of significant toxicity and lack of effectiveness. ${ }^{3,4}$ High-dose interleukin-2 (IL-2) has been shown to achieve long-lasting responses in a small subset of patients but is also associated with significant toxicity, and an overall survival (OS) advantage has not been conclusively demonstrated. ${ }^{5,6}$ Targeted therapies approved for the treatment of patients with advanced RCC, such as the vascular endothelial growth factor inhibitors sorafenib, bevacizumab, sunitinib, and pazopanib, as well as the mammalian target of rapamycin inhibitors temsirolimus ${ }^{7}$ and everolimus, ${ }^{8}$ 


\begin{tabular}{|c|c|c|c|c|}
\hline & \multicolumn{2}{|c|}{ Pazopanib } & \multicolumn{2}{|c|}{ Sunitinib } \\
\hline \multicolumn{5}{|l|}{ Weibull survival function parameters ${ }^{a}$} \\
\hline \multicolumn{5}{|l|}{ Progression-free survival } \\
\hline Lambda $(\lambda)$ & \multicolumn{2}{|c|}{0.0425} & \multicolumn{2}{|c|}{0.0530} \\
\hline $\operatorname{Gamma}(\gamma)$ & \multicolumn{2}{|c|}{1.1781} & \multicolumn{2}{|c|}{1.0920} \\
\hline \multicolumn{5}{|l|}{ Overall survival } \\
\hline Lambda $(\lambda)$ & \multicolumn{2}{|c|}{0.0118} & \multicolumn{2}{|c|}{0.0162} \\
\hline Gamma $(\gamma)$ & \multicolumn{2}{|c|}{1.2093} & \multicolumn{2}{|c|}{1.1271} \\
\hline \multicolumn{5}{|l|}{ Utility values, mean (SE) } \\
\hline On-treatment & 0.7487 & $(0.027)^{\mathrm{b}}$ & 0.6325 & $(0.043)^{\mathrm{b}}$ \\
\hline Off-treatment & N/Ac & & 0.8103 & $(0.029)^{\mathrm{c}}$ \\
\hline Combined & 0.7487 & $(0.027)$ & 0.6918 & $(0.030)$ \\
\hline Unit price of drugd (WAC per tablet/capsule), \$ & \multicolumn{2}{|c|}{59.42} & \multicolumn{2}{|c|}{384.34} \\
\hline Mean daily cost of drug, $\$$ & \multicolumn{2}{|c|}{237.68} & \multicolumn{2}{|c|}{256.23} \\
\hline \multicolumn{5}{|c|}{ Monthly costs of other care associated with pazopanib and sunitinib treatment, mean (SE), \$ } \\
\hline Hospital days & 509.27 & $(92.14)$ & 690.61 & $(117.72)$ \\
\hline Medical office visits & 23.61 & $(2.97)$ & 24.99 & $(3.17)$ \\
\hline Medical/surgical specialty visits & 16.59 & $(3.20)$ & 18.72 & $(3.56)$ \\
\hline Telephone consultations & 7.59 & $(1.11)$ & 7.07 & $(0.83)$ \\
\hline Urgent care visits & 4.90 & $(0.52)$ & 7.80 & $(0.73)$ \\
\hline Home health visits & 1.26 & $(0.44)$ & 5.11 & $(3.18)$ \\
\hline Laboratory visits & 3.19 & $(0.40)$ & 4.12 & $(0.49)$ \\
\hline Laboratory tests & 15.58 & $(2.53)$ & 20.20 & $(4.07)$ \\
\hline Radiology & 102.53 & $(6.48)$ & 134.58 & $(9.27)$ \\
\hline Total & $684.53^{\mathrm{e}}$ & $(78.54)$ & $913.18^{\mathrm{e}}$ & $(89.09)$ \\
\hline Mean cost of PTACT per patient in the COMPARZ trial, $\$$ & \multicolumn{2}{|c|}{57,839} & \multicolumn{2}{|c|}{59,783} \\
\hline \multicolumn{5}{|c|}{$\begin{array}{l}\text { aThe Weibull survival distribution takes the form } S[t]=e^{-\lambda t} \text {. } \\
\text { bThe percentage of treatment time was } 100 \% \text { and } 67 \% \text { for patients in the pazopanib and sunitinib groups, respectively. } \\
\text { 'The percentage of off-treatment time was } 0 \% \text { and } 33 \% \text { for patients in the pazopanib and sunitinib groups, respectively. } \\
\text { dSource: REDBOOK Online } 22 \text { (pazopanib } 200 \mathrm{mg} \text {; sunitinib } 50 \mathrm{mg} \text { ). } \\
\text { eNumbers do not add up exactly because of rounding. } \\
\text { COMPARZ = Comparing the Efficacy, Safety and Tolerability of Pazopanib versus Sunitinib; mg=milligram; N/A=not available; PTACT=post-treatment anticancer } \\
\text { therapy; SE = standard error; WAC= wholesale acquisition cost. }\end{array}$} \\
\hline
\end{tabular}

have demonstrated improved progression-free survival (PFS) compared with immunotherapy or placebo in both the firstline and/or second-line settings. $3,9-10$

Sunitinib (Sutent, Pfizer) is administered orally as 50 milligrams (mg) once daily in a 4-week-on/2-week-off schedule. ${ }^{10}$ Pazopanib (Votrient, GlaxoSmithKline) is administered at a dose of $800 \mathrm{mg}$ given orally once daily. ${ }^{9}$ Both drugs have similar mechanisms of action and have demonstrated efficacy in separate phase III trials with differences in the adverse event (AE) profiles. ${ }^{11-14}$

Pazopanib has been directly compared with sunitinib in 2 phase III randomized trials in patients with advanced/metastatic renal cell carcinoma (mRCC) who had not received prior treatment. The COMPARZ trial (Comparing the Efficacy, Safety and Tolerability of Pazopanib versus Sunitinib; ClinicalTrials. gov identifier: NCT00720941) was a randomized, open-label, parallel-group study that demonstrated noninferiority of pazopanib compared with sunitinib with regard to PFS. Patients receiving pazopanib had statistically significantly better scores in 11 of 14 health-related quality-of-life (HRQoL) comparisons ${ }^{15}$ and had nominally lower rates of nonstudy medical resource utilization (MRU) compared with patients receiving sunitinib during the first 6 months of treatment.

The PISCES trial (Patient Preference Study of Pazopanib versus Sunitinib in Advanced or Metastatic Kidney Cancer; ClinicalTrials.gov identifier: NCT01064310) was a doubleblind, crossover study that assessed patients' preferences for pazopanib versus sunitinib. ${ }^{16}$ Patients were randomized to receive pazopanib or sunitinib for 10 weeks of treatment in period 1 , followed by a 2 -week washout period, then 10 additional weeks of treatment with the alternative therapy in period 2. Results showed that patients and physicians preferred pazopanib primarily because it offered better HRQoL and caused less fatigue. ${ }^{16,17}$ The PISCES trial was not designed to measure or compare the clinical efficacy of either pazopanib or sunitinib. 


\section{FIGURE 1 Survival Distributions for PFS and OS Used in the Model}
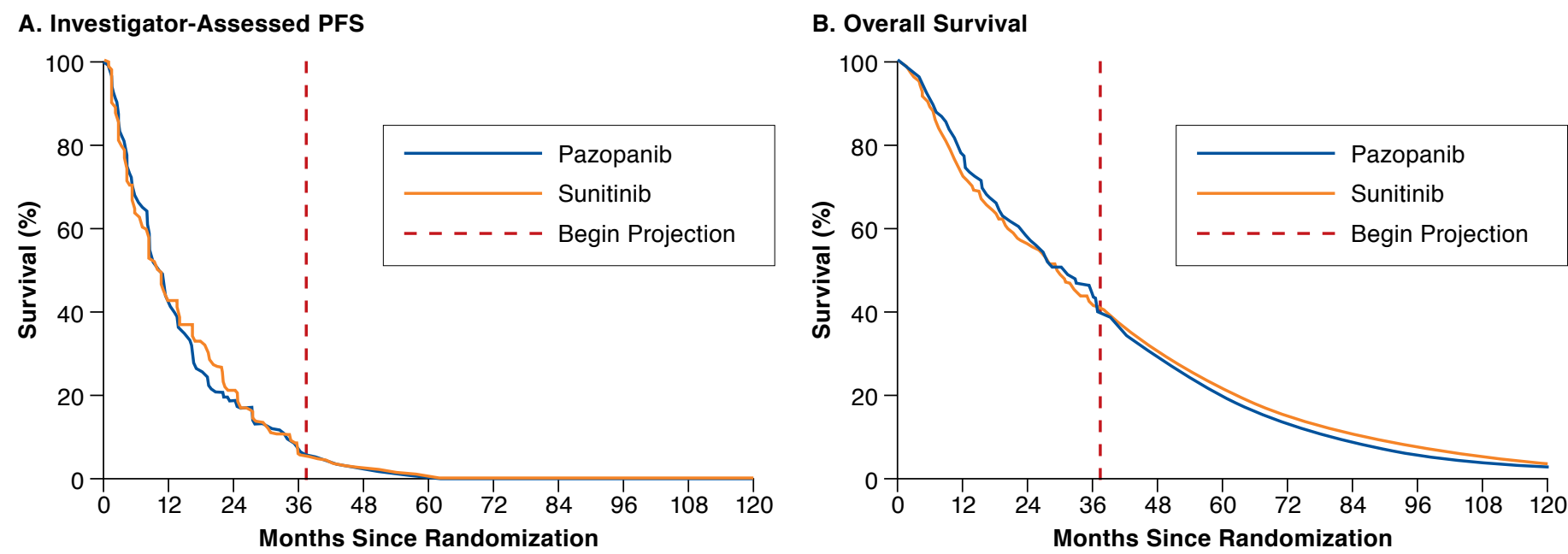

OS = overall survival; $P F S=$ progression-free survival

The objective of this study was to compare the cost-effectiveness of pazopanib versus sunitinib as the first-line treatment of patients with mRCC from a U.S. health care system perspective based on results from the COMPARZ and PISCES trials.

\section{Methods}

\section{Overview}

A partitioned-survival analysis model with 3 health statesalive with no progression (preprogression), alive with progression (postprogression), and dead-was used to calculate the expected costs, life-years, and quality-adjusted life-years (QALYs) for patients receiving pazopanib and sunitinib as the first-line treatment for mRCC. The population of interest was treatment-naive patients with mRCC. The only comparators of interest were pazopanib and sunitinib. Although sorafenib, bevacizumab (in combination with IFN- $\alpha$ ), and temsirolimus are also approved for use in the United States and European Union as first-line treatments of advanced/mRCC, comparisons with these agents would have required an indirect treatment comparison, which represents a lower level of evidence than the direct comparison examined in the COMPARZ trial. A U.S. health care system perspective was employed. Only direct medical costs associated with pazopanib and sunitinib treatment were considered. All cost estimates were in 2013 U.S. dollars. ${ }^{18}$ The time horizon of the analysis was 37.5 months (163 weeks), consistent with the latest time point for which survival time data were available for PFS and OS in both groups of the COMPARZ trial as of May 21, 2012, the data cut-off date. Sensitivity analyses were conducted using a 10-year time horizon.
In the model, the proportion of patients in each health state over time was calculated based on survival functions for PFS and OS. Postprogression survival (PPS) was calculated as the difference between OS and PFS. Costs and HRQoL were assumed to be conditioned on treatment and expected time in the progression-free and postprogression disease states. The model cycle length was 1 week, which was chosen to accommodate the 4-week treatment cycle for pazopanib and the 6 -week treatment cycle for sunitinib and to avoid the need for a half-cycle correction.

The model was used to generate estimates of expected lifetime costs including medication costs, dispensing/administration costs, other costs associated with pazopanib and sunitinib treatment (defined later and outlined in Table 1), routine follow-up, monitoring and supportive care costs, and total costs. Preprogression, postprogression, overall life expectancy (i.e., progression-free, postprogression, and overall life-years), and QALYs for pazopanib and sunitinib were also estimated. Effectiveness measures were calculated on undiscounted and discounted bases; costs were calculated on a discounted basis. An annual discount rate of 3\% was used. ${ }^{19}$ The incremental cost-effectiveness ratio (ICER) for pazopanib versus sunitinib was defined as the ratio of the difference (pazopanib versus sunitinib) in total costs to the difference in QALYs (incremental cost per QALY gained). The net monetary benefit (NMB) of pazopanib versus sunitinib was also calculated for different levels of the threshold value of cost-effectiveness $(\$ 50,000$, $\$ 100,000$, and $\$ 200,000$ per QALY gained). ${ }^{20}$ 


\section{Model Estimation}

Model inputs are summarized in Table 1. Survival functions out to 37.5 months for PFS and OS were estimated based on Kaplan-Meier (KM) survival distributions from the COMPARZ trial (Figure 1). For sensitivity analyses using a 10-year time frame, PFS and OS beyond 37.5 months were based on Weibull survival functions fit to individual patient data from the COMPARZ trial using accelerated failure time regression. Investigator-assessed PFS, rather than independent review committee (IRC)-assessed PFS, was used because the former is more likely to accurately reflect assessment of disease progression during the course of routine clinical practice. Also, IRC-assessed PFS may introduce bias because of informative censoring of nonconfirmed locally determined progressions. ${ }^{21}$

The COMPARZ trial did not include a preference-based assessment of HRQoL. In the PISCES trial, the EuroQol 5-dimension (EQ-5D) questionnaire, a preference-based measure of HRQoL, was administered at baseline, the end of the 2-week washout period, and week 10 of the second treatment period. ${ }^{16}$ Utility values for the PFS state for pazopanib and sunitinib were therefore estimated based on EQ-5D data from the PISCES trial. ${ }^{17}$ For pazopanib, the utility value at week 10 of period 2 for the sunitinib-pazopanib group was used. For sunitinib, a weighted average of the mean (standard error $[\mathrm{SE}]$ ) utility value at week 10 of the second treatment period for the pazopanib-sunitinib group (0.6325 [0.043]) and the utility value during the washout period for the sunitinib-pazopanib group was used $(0.8103$ [0.029]). The former reflects utility during the sunitinib on-treatment period, and the latter reflects utility during the sunitinib off-treatment period. The weights (66.6\% and $33.3 \%$, respectively) were calculated to reflect the relative duration of the sunitinib on- and off-treatment periods (i.e., 28/42 days and 14/42 days, respectively). Because patients were not followed after progression in the PISCES trial, the utility value for the postprogression state was assumed to be the same for pazopanib and sunitinib and was estimated based on the mean EQ-5D utility value after termination of secondline therapy in the sunitinib phase III trial. ${ }^{22}$

Unit costs of pazopanib and sunitinib were based on published wholesale acquisition costs (WAC) that reflect manufacturer list prices. ${ }^{23}$ Pazopanib and sunitinib were assumed to be dispensed every 4 and 6 weeks, respectively. In calculating medication costs, it was assumed that any medication supplied but not taken was discarded (i.e., the cost of a full prescription was incurred on the first day of each treatment cycle). Patients were assumed to require a single visit per cycle for administration of oral therapy at a cost of $\$ 75.77$ per visit based on the national average Medicare fee for an office visit (Current Procedural Terminology, 4th edition (CPT-4) 99214: Office evaluation and management involving decision making of moderate complexity). ${ }^{24}$ The cost of dispensing each prescription was assumed to be $\$ 10.50 .^{25}$ Based on these prices and planned dosages, the average cost per 6 weeks of therapy was estimated to be $\$ 9,983$ for pazopanib and $\$ 10,762$ for sunitinib. Medication costs were adjusted for dose intensity using the ratio of the mean actual dose versus the mean planned cumulative dose-over all days of follow-up-of pazopanib (68\%) and sunitinib (67\%) in the COMPARZ trial. Dispensing costs were adjusted by the ratio of the mean actual versus mean planned cumulative number of cycles with pazopanib (78\%) and sunitinib $(79 \%)$ in the COMPARZ trial. These adjustments account for dose reductions, treatment interruptions, and treatment discontinuation before and/or after disease progression.

Other costs associated with pazopanib and sunitinib treatment were estimated by combining monthly rates of nonstudy MRU from the COMPARZ trial with unit cost estimates from published or publically available sources. ${ }^{26}$ Costs of nonstudy medical office visits, laboratory visits and tests, radiological visits and tests, home health visits, hospital days (general ward or intensive care unit), and emergency department visits were assumed to be incurred each month until progression. These cost differences were not assessed for statistical significance.

The estimated cost of a day in the general ward was based on the per diem cost of hospitalizations with a primary diagnosis International Classification of Diseases, Ninth Revision, Clinical Modification (ICD-9-CM) code of 189.0-malignant neoplasm of kidney except renal pelvis-and with a nonsurgical principal procedure from the Healthcare Costs and Utilization Project National Inpatient Sample database. ${ }^{27}$ The estimated cost of a day in the intensive care unit was taken from a 2010 retrospective analysis of critical care costs using Medicare hospital cost reports. ${ }^{28}$ Costs of primary care physician; nurse practitioner/physician's assistant/nurse; and specialist visits, telephone consultations, and radiological tests were taken from the 2013 Medicare Physician Fee Schedule. ${ }^{25}$ Costs of all primary care and specialist visits were assumed to correspond to CPT-4 code 99214-an office visit involving decision making of moderate complexity. Nurse practitioner/physician's assistant/nurse visits were assigned the costs of CPT-4 99211 (an outpatient visit that may not require the presence of a physician, presenting problems are minimal); telephone consultations were assigned the cost of CPT-4 99212 (an office visit involving straightforward decision making). Costs of emergency department visits were from a 2005 study that used hospital discharge reports to estimate the cost of an emergency department visit. ${ }^{29}$ Costs of laboratory services were from the 2013 Medicare Clinical Laboratory Fee Schedule. ${ }^{30}$ The costs of positron emission tomography (PET) and PET/computed tomography scans were based on the costs of CPT-4 78811 (tumor imaging using PET over a limited area) as reported in a General Electric Healthcare publication, which provides the 2013 national Medicare physician fee schedule and facility payment rates for such scans. ${ }^{31}$ The costs of "other" nonspe- 


\section{TABLE 2 Base-Case Results}

\begin{tabular}{|c|c|c|c|}
\hline & Pazopanib & Sunitinib & Difference \\
\hline \multicolumn{4}{|l|}{ Effectiveness (not discounted), \$ } \\
\hline Progression-free life-years & 1.130 & 1.147 & -0.017 \\
\hline Postprogression life-years & 0.993 & 0.921 & 0.072 \\
\hline Life-years & 2.122 & 2.068 & 0.054 \\
\hline QALYs & 1.393 & 1.301 & 0.092 \\
\hline \multicolumn{4}{|l|}{ Effectiveness (discounted), \$ } \\
\hline Progression-free life-years & 1.113 & 1.130 & -0.016 \\
\hline Postprogression life-years & 0.957 & 0.887 & 0.069 \\
\hline Life-years & 2.070 & 2.017 & 0.053 \\
\hline QALYs & 1.361 & 1.270 & 0.090 \\
\hline \multicolumn{4}{|l|}{ Costs (discounted), \$ } \\
\hline Study medication & 68,209 & 74,473 & $-6,264$ \\
\hline Administration/dispensing & 1,008 & 707 & 301 \\
\hline Other costs associated with pazopanib and sunitinib treatment ${ }^{\mathrm{a}}$ & 9,147 & 12,381 & $-3,234$ \\
\hline Preprogression routine follow-up & 29,926 & 30,365 & -439 \\
\hline Postprogression routine follow-up & 46,269 & 43,460 & 2,809 \\
\hline Total & 154,559 & 161,387 & $-6,828$ \\
\hline Incremental cost per QALY gained, \$ & & & Dominant \\
\hline \multicolumn{4}{|l|}{ NMB by threshold for cost-effectiveness, $\$$} \\
\hline$\$ 50,000$ per QALY gained & & & 11,343 \\
\hline$\$ 100,000$ per QALY gained & & & 15,857 \\
\hline$\$ 200,000$ per QALY gained & & & 24,886 \\
\hline
\end{tabular}

cific services or tests were assigned the average cost of related specific services or tests. Unit cost estimates for all services are provided in the Appendix (available in online article).

Combining treatment group-specific estimates of mean (SE) nonstudy MRU from the COMPARZ trial and the unit cost estimates just described, the mean (SE) monthly costs of nonstudy MRU associated with pazopanib and sunitinib were estimated to be $\$ 684.53$ (\$78.54) and \$913.18 (\$89.09), respectively, implying a difference of $\$ 228.65$ per month for sunitinib versus pazopanib. Costs were not assigned to specific AEs, since it was assumed that the costs of nonstudy MRU reflected any differences between pazopanib and sunitinib in efficacy and safety. Routine follow-up, progression, and supportive care costs were obtained from an economic evaluation of sunitinib for the first-line treatment of mRCC. ${ }^{32}$ The costs of post-treatment anticancer therapy (PTACT) for pazopanib and sunitinib were included in a sensitivity analyses and were estimated based on utilization data in the COMPARZ trial and published list prices. ${ }^{23}$

\section{Analyses}

Probabilistic Sensitivity Analyses. Probabilistic sensitivity analyses were conducted by simultaneously sampling from estimated probability distributions of model parameters to obtain 1,000 sets of model input estimates. ${ }^{33,34}$ PFS and OS were sampled from bootstrapped KM survival distributions. For sampled distributions of PFS and OS where the maximum follow-up was less than 37.5 months, PFS and OS from the end of follow-up to 37.5 months were estimated by extrapolation using Weibull distributions fitted to the data from the corresponding bootstrap sample. The utility for PFS was assumed to be distributed as a beta random variable. The decrement in utility for PPS versus PFS was assumed to be distributed as a normal random variable. Unit costs of medications, dispensing, and administration were not sampled. Costs of routine follow-up, progression, and terminal phase were assumed to be distributed as lognormal random variables with SEs assumed to be 0.25 times the base-case estimate. Costs of nonstudy MRU from the COMPARZ trial were distributed as log-normal variables. For each simulation, calculations were performed to derive the expected costs and QALYs for pazopanib and sunitinib; differences in expected costs and QALYs between pazopanib and sunitinib; and the incremental cost per QALY gained with pazopanib versus sunitinib. For expected costs and QALYs and the differences in expected costs and QALYs, 95\% confidence intervals (CIs) were calculated based on the 2.5 and 97.5 percentiles of these simulations. Simulation results were plotted on a cost-effectiveness plane for each comparison, and cost-effectiveness acceptability curves were constructed for pazopanib versus sunitinib to identify the proportion of simulations for which pazopanib was 


\section{A. Scatter Plot of Incremental Costs and QALYs}

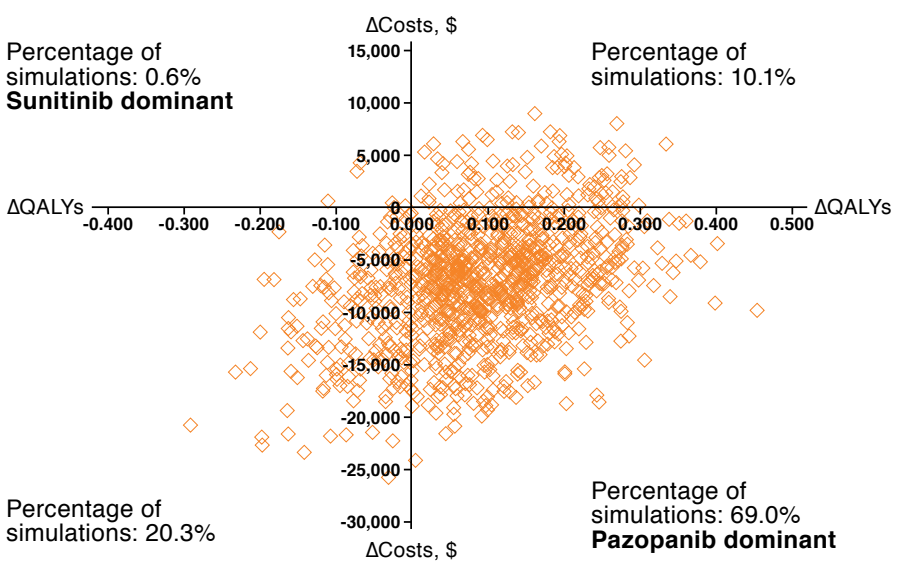

\section{B. Acceptability Curves for Pazopanib and Sunitinib}

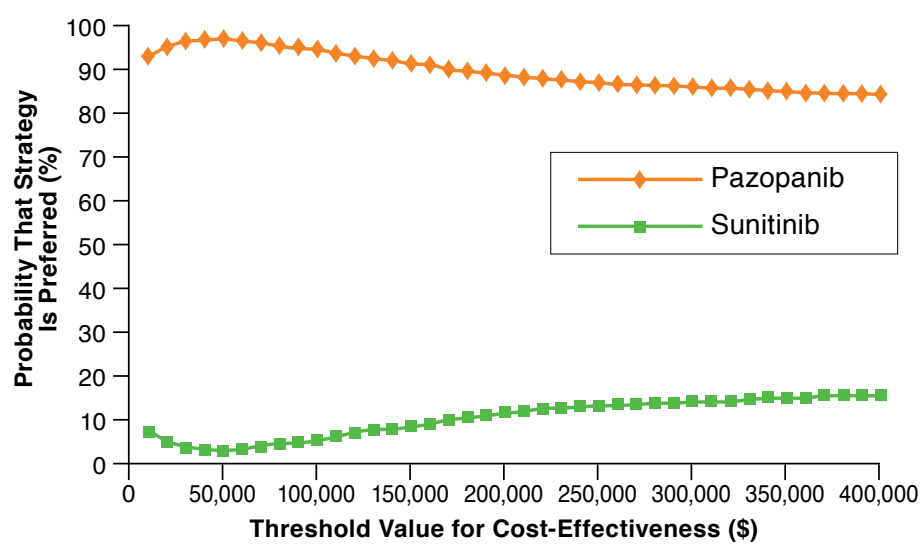

QALYs = quality-adjusted life-years.

preferred given various levels of decision makers' threshold values for cost per QALY gained. ${ }^{35}$

Deterministic Sensitivity Analyses. Deterministic sensitivity analyses were conducted to explore the impact of changing key parameter values on the ICER and NMB of pazopanib versus sunitinib. A variety of scenarios were evaluated encompassing the following parameters: time horizon, PFS, OS, relative dose intensity, administration/dispensing costs, monthly costs, decrements in utility, and discount rates. When calculating NMB in deterministic sensitivity analyses, the threshold value for cost-effectiveness was defined as $\$ 100,000$ per QALY.

No institutional review board approval was performed, since this study was a post hoc cost-effectiveness analysis of a previously approved clinical trial using de-identified records.

\section{Results}

Because pazopanib was estimated to provide more QALYs at a lower cost compared with sunitinib, it was dominant compared with sunitinib in the base case (Table 2). The NMB of pazopanib versus sunitinib was $\$ 11,343, \$ 15,857$, and $\$ 24,886$ at threshold values of cost-effectiveness of $\$ 50,000, \$ 100,000$, and $\$ 200,000$ per QALY gained, respectively. At a threshold value of $\$ 100,000$ per QALY gained, 43\% of the NMB was due to reduced costs (savings of $\$ 6,828$ ), and $57 \%$ was a consequence of increased QALYs (0.090 QALYs gained "monetized" at a value of $\$ 100,000$ per QALY equals $\$ 9,000$ ).

In the probabilistic sensitivity analyses, the median difference in expected cost for pazopanib versus sunitinib was -\$7,078 (95\% CI =-\$18,771-\$4,394; Figure 2A). The median difference in expected QALYs for pazopanib versus sunitinib was 0.088 (95\% CI $=-0.128-0.286)$. At a threshold value of cost-effectiveness of $\$ 100,000$ per QALY gained, the median NMB for pazopanib versus sunitinib was \$16,027 (95\% $\mathrm{CI}=-\$ 3,614-\$ 36,302)$. In $69 \%$ of the simulations, pazopanib was projected to yield more QALYs and lower costs compared with sunitinib (pazopanib is dominant). Pazopanib was projected to yield higher costs and lower QALYs (sunitinib is dominant) in $1 \%$ of the simulations. Pazopanib was projected to yield more QALYs in 79\% of the simulations and lower costs in $89 \%$ of the simulations.

Acceptability curves for pazopanib and sunitinib are shown in Figure 2B. The probability that pazopanib is cost-effective versus sunitinib was estimated to be $97 \%$ for a threshold value of cost-effectiveness of $\$ 50,000$ per QALY gained; 94\% for a threshold value of cost-effectiveness of $\$ 100,000$ per QALY gained; and $88 \%$ for a threshold value of cost-effectiveness of $\$ 200,000$ per QALY gained. The probability that pazopanib is cost-effective versus sunitinib was estimated to be $90 \%$ or more for cost-effectiveness thresholds between $\$ 10,000$ and $\$ 160,000$ per QALY gained.

In deterministic sensitivity analyses (NMB calculated using a threshold value of $\$ 100,000$ per QALY), the NMB for pazopanib versus sunitinib was estimated to range from $\$ 8,292$ to $\$ 20,933$. NMB was most sensitive to assumptions regarding costs associated with pazopanib and sunitinib treatment and the utility values for sunitinib and pazopanib (Figure 3). NMB was more favorable when the costs of PTACT were included and when a 10-year time horizon was used and less favorable when the utility values for sunitinib were assumed to be the same as those for pazopanib. The NMB of pazopanib versus sunitinib was positive in all scenarios examined. 
Disutility for PFS vs. perfect health $\pm 50 \%$ of base case ca $^{a}$ Sunitinib utility values $=$ pazopanib utility values Sunitinib PFS utility = pazopanib PFS utility Disutility for PPS vs. PFS $\pm 50 \%$ of base case ${ }^{b}$ Other costs associated with pazopanib and sunitinib $\pm 50 \%$ of base case ${ }^{a}$ Other costs associated with sunitinib set $=$ costs assocated with pazopanib PPS cost $\pm 50 \%$ of base case ${ }^{b}$ PTACT costs included Sunitinib RDIs = pazopanib RDI Pazopanib RDIs = sunitinib RDI Sunitinib PFS and OS = pazopanib PFS and OS Sunitinib OS = pazopanib OS Time horizon 10 years, PFS/OS to 37 months using KM with Weibull extrap.

Discount rate $0 \%-5 \%{ }^{\mathrm{b}}$

Sunitinib PFS = pazopanib PFS

Treatment initiation/routine follow-up cost $\pm 50 \%$ of base case ${ }^{a}$ Administration/dispensing costs $\pm 50 \%$ of base case ${ }^{b}$ Time horizon 10 years, PFS/OS using Weibull for entire time horizon Using IRC-assessed rather than investigator-assessed PFS

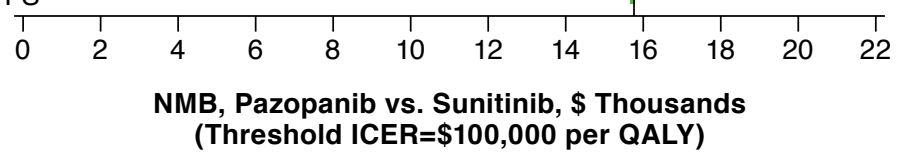

aLow value of parameter corresponds to low value of NMB; high value of parameter corresponds to high value of NMB.

${ }^{b}$ Low value of parameter corresponds to high value of NMB; high value of parameter corresponds to low value of NMB.

$I C E R=$ incremental cost-effectiveness ratio; $I R C=$ independent review committee; $K M=$ Kaplan-Meier; $N M B=$ net monetary benefit; OS = overall survival; $P F S=$ progression-free survival; PPS = postprogression survival; $P T A C T=$ post-treatment anticancer therapy; $Q A L Y=$ quality-adjusted life-year; $R D I=$ relative dose intensity.

\section{Discussion}

This study evaluated the cost-effectiveness of pazopanib versus sunitinib as the first-line treatment for mRCC from a U.S. health care system perspective. Using PFS, OS, and MRU data from the COMPARZ study; utilities data from the PISCES trial; and published cost estimates, pazopanib was projected to yield more QALYs at a lower cost compared with sunitinib. Therefore, pazopanib was estimated to be dominant compared with sunitinib in the base case. At a cost-effectiveness threshold value of $\$ 100,000$ per QALY gained, the NMB with pazopanib versus sunitinib was estimated to be $\$ 15,857$.

Probabilistic sensitivity analyses showed a $90 \%$ or greater probability of pazopanib being cost-effective versus sunitinib for cost-effectiveness threshold values between $\$ 10,000$ and $\$ 160,000$ per QALY gained. In all scenarios tested in the deterministic sensitivity analyses, which included decrements in utility values, the NMB of pazopanib versus sunitinib was always positive and favored pazopanib.
The model used in this evaluation was similar to one employed to examine the cost-effectiveness of pazopanib versus best supportive care, IFN- $\alpha$, and sunitinib as first-line treatment for advanced/mRCC from a United Kingdom National Health Service perspective in the manufacturer's submission to the National Institute for Health and Care Excellence (NICE) ${ }^{36}$ In the final analyses performed by the evidence review group (ERG) using the manufacturer's model and assuming a 12.5\% discount to the list price for pazopanib, pazopanib was more costly and more effective than sunitinib and had a cost-effectiveness ratio ranging from $£ 1,790$ to $£ 5,330$ per QALY gained. Given a cost-effectiveness threshold value of $£ 30,000$, there was a $54 \%$ probability that pazopanib was preferred to sunitinib. However, the results of the comparison of pazopanib and sunitinib reported in the current analysis are associated with substantially less uncertainty than those reported by Kilonzo et al. (2013), since this study is based on a single, direct comparison of pazopanib and sunitinib, whereas the NICE analyses were based on an indirect treatment comparison of trials of pazopanib versus placebo, IFN versus placebo, and sunitinib 
versus IFN. ${ }^{36}$ Moreover, the trial of pazopanib versus placebo used in Kilonzo et al. was confounded by crossover. ${ }^{36}$ The uncertainty in the prior analyses were noted by the ERG and recognized by the Appraisal Committee and were reflected in their positive recommendations for pazopanib contingent on the outcome of the COMPARZ trial.

\section{Limitations}

This study has some limitations. First, this study compared pazopanib and sunitinib only and did not evaluate the costeffectiveness of other therapies that may be approved for use as first-line treatment of advanced/mRCC in the United States. Comparisons with these agents would have required an indirect treatment comparison, which represents a lower level of evidence than the direct comparison of pazopanib versus sunitinib in the COMPARZ trial, which was the primary basis of this evaluation.

The estimated benefits of pazopanib on QALYs were derived from the assumed differences in utility values between patients who received pazopanib versus those who received sunitinib. Because the COMPARZ trial did not include a preference-based HRQoL assessment, utility values from the PISCES trial were used in the model. Data from the PISCES trial represent the only data on EQ-5D utilities for pazopanib and sunitinib drawn from a clinical trial. However, because of the design of the study and the way the data from the study were utilized, the differences in utility values for pazopanib and sunitinib used in this analysis were not based on a randomized comparison. Nevertheless, the estimated benefits of pazopanib on HRQoL in the model are consistent with other results of the PISCES and COMPARZ studies with regard to patient preferences and HRQoL. ${ }^{15,16}$ The differences in AEs between treatment groups in the PISCES trial were consistent with those in the COMPARZ trial, supporting the notion that utility values from the PISCES trial likely reflect those that would have been obtained from the COMPARZ trial if utility data had been collected.

The estimated cost savings associated with pazopanib in this analysis are largely due to the assumed lower WAC of pazopanib versus sunitinib, as well as the lower estimated monthly costs of other services related to treatment of mRCC based on MRU data from the COMPARZ trial. The actual prices paid for each drug may differ across payers and health care systems in the United States and may not reflect those used in our analysis. Because COMPARZ was a multinational trial, the MRU in the trial may not reflect utilization in all settings.

\section{Conclusions}

The results of this cost-effectiveness analysis based on a survival analysis model employing data from 2 randomized phase III clinical trials comparing pazopanib with sunitinib suggest that pazopanib is cost-effective compared with sunitinib as a first-line treatment of patients with mRCC in the United States.

\section{Authors}

THOMAS E. DELEA, MSIA, is Senior Research Consultant, and JORDAN AMDAHL, BS, is Senior Research Assistant, Policy Analysis Inc., Brookline, Massachusetts. JOSE DIAZ, MD, MSc, is Director, Global Health Outcomes Oncology, GlaxoSmithKline, Stockley Park West, Uxbridge, Middlesex, United Kingdom; HAMID REZA NAKHAIPOUR, MD, MSc, PhD, is Health Outcomes Manager, Medical Division, GlaxoSmithKline, Mississauga, Ontario, Canada; and MICHELLE D. HACKSHAW, BScPharm, MSHS, $\mathrm{PhD}$, is Director, U.S. Health Outcomes Oncology, GlaxoSmithKline, Philadelphia, Pennsylvania.

AUTHOR CORRESPONDENCE: Thomas E. Delea, MSIA, Senior Research Consultant, Policy Analysis Inc., Four Davis Ct., Brookline, MA 02445. Tel.: 617.232.4400; Fax: 617.232.1155;

E-mail: tdelea@pai2.com.

\section{DISCLOSURES}

Funding for this study was provided to Policy Analysis Inc. (PAI) by GlaxoSmithKline (GSK). All listed authors meet the criteria for authorship set forth by the International Committee for Medical Journal Editors. Delea and Amdahl are employees of PAI, which has received research funding and consulting fees from GSK for activities related to this study, and have received support for travel to meetings to present these study results. PAI also received consulting fees and research funding from GSK for activities unrelated to this study. Diaz, Nakhaipour, and Hackshaw are employees of GSK. Diaz and Hackshaw hold stock in GSK.

Study concept and design were contributed by Delea, Diaz, Hackshaw Amdahl, and Nakhaipour. Delea, Amdahl, and Hackshaw were primarily responsible for data interpretation, along with Diaz and Nakhaipour. The manuscript was written by Delea, Hackshaw, Diaz, Nakhaipour, and Amdahl and revised primarily by Delea, Nakhaipour, and Hackshaw, with assistance from Amdahl and Diaz.

\section{ACKNOWLEDGMENTS}

The authors wish to thank Nate Fedor of PAI, who assisted with the analyses The authors wish to acknowledge Prasad Kulkarni, PhD, and Nancy Price, $\mathrm{PhD}$, of AOI Communications, L.P., for editorial support (assembling tables and figures, collating author comments, copyediting, fact checking, and referencing) and graphic services, which were funded by GSK.

\section{REFERENCES}

1. Cohen HT, McGovern FJ. Renal-cell carcinoma. N Engl J Med. 2005;353(23):2477-90.

2. Siegel R, Ma J, Zou Z, Jemal A. Cancer statistics, 2014. CA Cancer J Clin. 2014;64(1):9-29. Available at: http://onlinelibrary.wiley.com/doi/10.3322/ caac.21208/pdf. Accessed November 24, 2014.

3. Coppin C, Kollmannsberger C, Le L, Porzsolt F, Wilt TJ. Targeted therapy for advanced renal cell cancer (RCC): a Cochrane systematic review of published randomised trials. BJU Int. 2011;108(10):1556-63.

4. Motzer RJ, Russo P. Systemic therapy for renal cell carcinoma. J Urol. 2000;163(2):408-17.

5. McDermott DF, Regan MM, Clark JI, et al. Randomized phase III trial of high-dose interleukin-2 versus subcutaneous interleukin-2 and interferon in patients with metastatic renal cell carcinoma. J Clin Oncol. 2005;23(1):133-41. Available at: http://jco.ascopubs.org/content/23/1/133.full.pdf+html. Accessed November 24, 2014. 
6. Yang JC, Sherry RM, Steinberg SM, et al. Randomized study of high-dose and low-dose interleukin-2 in patients with metastatic renal cancer. J Clin Oncol. 2003;21(16):3127-32. Available at: http://www.ncbi.nlm.nih.gov/pmc/ articles/PMC2275327/. Accessed December 9, 2014.

7. Torisel (temsirolimus) injection. Pfizer Inc. Revised October 2014. Available at: http://labeling.pfizer.com/showlabeling.aspx?id=490. Accessed November 24, 2014.

8. Afinitor (everolimus) tablets. Novartis Pharmaceuticals Corporation. Revised July 2014. Available at: http://www.pharma.us.novartis.com/product/pi/pdf/afinitor.pdf. Accessed November 24, 2014.

9. Votrient (pazopanib) tablets. GlaxoSmithKline. Revised June 2014. Available at: https://www.gsksource.com/gskprm/htdocs/documents/ VOTRIENT-PI-MG.PDF. Accessed November 24, 2014

10. Sutent (sunitinib malate) capsules, oral. Pfizer Inc. Revised June 2014. Available at: http://labeling.pfizer.com/ShowLabeling.aspx?id=607. Accessed November 24, 2014.

11. Motzer RJ, Hutson TE, Tomczak P, et al. Overall survival and updated results for sunitinib compared with interferon alfa in patients with metastatic renal cell carcinoma. J Clin Oncol. 2009;27(22):3584-90. Available at: http://jco.ascopubs.org/content/27/22/3584.full.pdf+html. Accessed November 24, 2014.

12. Motzer RJ, Hutson TE, Tomczak P, et al. Sunitinib versus interferon alfa in metastatic renal-cell carcinoma. N Engl J Med. 2007;356(2):115-24 Available at: http://www.nejm.org/doi/pdf/10.1056/NEJMoa065044. Accessed November 24, 2014

13. Sternberg CN, Davis ID, Mardiak J, et al. Pazopanib in locally advanced or metastatic renal cell carcinoma: results of a randomized phase III trial. J Clin Oncol. 2010;28(6):1061-68. Available at: http://jco.ascopubs.org/content/28/6/1061.full.pdf+html. Accessed November 24, 2014.

14. Sternberg CN, Hawkins RE, Wagstaff J, et al. A randomised, doubleblind phase III study of pazopanib in patients with advanced and/or metastatic renal cell carcinoma: final overall survival results and safety update. Eur J Cancer. 2013;49(6):1287-96.

15. Motzer RJ, Hutson TE, Cella D, et al. Pazopanib versus sunitinib in metastatic renal-cell carcinoma. N Engl J Med. 2013;369(8):722-31. Available at: http://www.nejm.org/doi/pdf/10.1056/NEJMoal303989. Accessed November 24, 2014.

16. Escudier B, Porta C, Bono P, et al. Randomized, controlled, double-blind, cross-over trial assessing treatment preferences for pazopanib versus sunitinib in patients with metastatic renal cell carcinoma: PISCES study. J Clin Oncol. 2014;32(14):1412-18.

17. GlaxoSmithKline. A randomised double-blind cross-over patient preference study of pazopanib versus sunitinib in treatment naive locally advanced or metastatic renal cell carcinoma. Result summary. 2012. Available at: http://www.gsk-clinicalstudyregister.com/study/113046\#ps. Accessed November 24, 2014

18. U.S. Department of Labor. Bureau of Labor Statistics. Consumer Price Index. Detailed Reports. Index for All Urban Consumers: Medical Care. 2013. Available at: http://www.bls.gov/cpi/tables.htm. Accessed December 9, 2014.

19. Gold M, Siegel J, Russell L, Weinstein M, eds. Cost-Effectiveness in Health and Medicine. New York: Oxford University Press; 1996.

20. Stinnett AA, Mullahy J. Net health benefits: a new framework for the analysis of uncertainty in cost-effectiveness analysis. Med Decis Making. 1998;18(2 Suppl):S68-S80. Available at: http://umg.umdnj.edu/smdm/ pdf/18-02-S68.pdf. Accessed November 24, 2014.

21. Dodd LE, Korn EL, Freidlin B, et al. Blinded independent central review of progression-free survival in phase III clinical trials: important design element or unnecessary expense? J Clin Oncol. 2008;26(22):3791-96. Available at: http://www.ncbi.nlm.nih.gov/pmc/articles/PMC2654812/pdf/7716.pdf. Accessed November 24, 2014
22. Truven Health Analytics Inc. REDBOOK Online. 2014. Available at: http://micromedex.com/redbook. Accessed December 9, 2014

23. Chabot I, Rocchi A. How do cost-effectiveness analyses inform reimbursement decisions for oncology medicines in Canada? The example of sunitinib for first-line treatment of metastatic renal cell carcinoma. Value Health. 2010;13(6):837-45. Available at: http://onlinelibrary.wiley.com/ doi/10.1111/j.1524-4733.2010.00738.x/pdf. Accessed November 24, 2014.

24. Centers for Medicare \& Medicaid Services. Physician fee schedule. Available at: http://www.cms.gov/apps/physician-fee-schedule/. Accessed November 24, 2014

25. Grant Thornton LLP. Cost of dispensing study: an independent comparative analysis of U.S. prescription dispensing costs. January 2007. Available at: http://mpi-group.com/wp-content/uploads/2012/05/ CostofDispensingStudy_GT.pdf. Accessed November 24, 2014.

26. Hansen RN, Hackshaw MD, Nager SP, et al. Health care costs among renal cancer patients using pazopanib and sunitinib. J Manag Care Pharm. 2015;21(1):37-44

27. Healthcare Costs and Utilization Project (HCUP). HCUP databases. National (nationwide) inpatient sample. November 2014. Agency for Healthcare Research and Quality, Rockville, MD. Available at: http://www. hcup-us.ahrq.gov/databases.jsp. Accessed November 24, 2014.

28. Halpern NA, Pastores SM. Critical care medicine in the United States 2000-2005: an analysis of bed numbers, occupancy rates, payer mix, and costs. Crit Care Med. 2010;38(1):65-71.

29. Bamezai A, Melnick G, Nawathe A. The cost of an emergency department visit and its relationship to emergency department volume. Ann Emerg Med. 2005;45(5):483-90.

30. Centers for Medicare \& Medicaid Services. Clinical laboratory fee schedule. Last modified September 4, 2014. Available at: http://www.cms gov/Medicare/Medicare-Fee-for-Service-Payment/ClinicalLabFeeSched/. Accessed November 24, 2014.

31. GE Healthcare. Reimbursement information for Positron Emission Tomography (PET). 2013. Available at: http://www3.gehealthcare.com/ en/content_gate/gating_form_-_short?id=\{A320408B-OFAF-4B0B-80ADC2D3F27D6D86\}. Accessed December 9, 2014.

32. Remák E, Charbonneau C, Négrier S, Kim ST, Motzer RJ. Economic evaluation of sunitinib malate for the first-line treatment of metastatic renal cell carcinoma. J Clin Oncol. 2008;26(24):3995-4000. Available at: http:// jco.ascopubs.org/content/26/24/3995.full.pdf + html. Accessed November 24,2014

33. Briggs AH. Handling uncertainty in cost-effectiveness models. Pharmacoeconomics. 2000;17(5):479-500.

34. Doubilet P, Begg CB, Weinstein MC, Braun P, McNeil BJ. Probabilistic sensitivity analysis using Monte Carlo simulation. A practical approach. Med Decis Making. 1985;5(2):157-77.

35. Löthgren M, Zethraeus N. Definition, interpretation and calculation of cost-effectiveness acceptability curves. Health Econ. 2000;9(7):623-30.

36. Kilonzo M, Hislop J, Elders A, et al. Pazopanib for the first-line treatment of patients with advanced and/or metastatic renal cell carcinoma: a NICE single technology appraisal. Pharmacoeconomics. 2013;31(1):15-24.

37. Centers for Medicare \& Medicaid Services. National physician fee schedule relative value files. Available at: http://www.cms.gov/Medicare/MedicareFee-for-Service-Payment/PhysicianFeeSched/PFS-Relative-Value-Files.html. Accessed November 24, 2014. 


\section{APPENDIX Unit Costs of Nonstudy Medical Resources in the COMPARZ Trial}

\begin{tabular}{|c|c|c|c|}
\hline Service & Cost $(\$)$ & Source $^{a}$ & Description $^{b}$ \\
\hline \multicolumn{4}{|l|}{ Medical office visits } \\
\hline Primary care physician visits & 75.77 & Medicare physician fee schedule 24 & $\begin{array}{l}\text { 99214: Office E\&M visit involving decision making of } \\
\text { moderate complexity }\end{array}$ \\
\hline $\begin{array}{l}\text { Nurse practitioner/physician's } \\
\text { assistant/nurse visits }\end{array}$ & 20.41 & Medicare physician fee schedule 24 & $\begin{array}{l}\text { 99211: Outpatient E\&M visit, that may not require the } \\
\text { presence of a physician, presenting problems are minimal }\end{array}$ \\
\hline Telephone consultations & 43.89 & Medicare physician fee schedule ${ }^{24}$ & $\begin{array}{l}\text { 99212: Office E\&M visit involving straightforward decision } \\
\text { making }\end{array}$ \\
\hline \multicolumn{4}{|l|}{ Medical/surgical special visits } \\
\hline Oncology, medical & 75.77 & Medicare physician fee schedule 24 & $\begin{array}{l}\text { 99214: Office E\&M visit involving decision making of } \\
\text { moderate complexity }\end{array}$ \\
\hline Hematology & 75.77 & Medicare physician fee schedule ${ }^{24}$ & $\begin{array}{l}\text { 99214: Office E\&M visit involving decision making of } \\
\text { moderate complexity }\end{array}$ \\
\hline Nononcology & 75.77 & Medicare physician fee schedule 24 & $\begin{array}{l}\text { 99214: Office E\&M visit involving decision making of } \\
\text { moderate complexity }\end{array}$ \\
\hline Other & 75.77 & Medicare physician fee schedule 24 & $\begin{array}{l}\text { 99214: Office E\&M visit involving decision making of } \\
\text { moderate complexity }\end{array}$ \\
\hline Laboratory visits & 23.82 & Medicare physician fee schedule ${ }^{24}$ & $\begin{array}{l}\text { 36591: Collection of blood specimen from venous access } \\
\text { device }\end{array}$ \\
\hline \multicolumn{4}{|l|}{ Specific laboratory tests } \\
\hline Hematology & 10.69 & Medicare clinical lab fee schedule ${ }^{30}$ & 85025: CBC with automated differential WBC \\
\hline Clinical chemistry & 14.53 & Medicare clinical lab fee schedule ${ }^{30}$ & $\begin{array}{l}\text { 80053: Comprehensive metabolic panel } \\
\text { Comprises: } \\
\text { Albumin (82040) } \\
\text { Bilirubin, total (82247) } \\
\text { Calcium, total (82310) } \\
\text { Carbon dioxide (bicarbonate) (82374) } \\
\text { Chloride (82435) } \\
\text { Creatinine (82565) } \\
\text { Glucose (82947) } \\
\text { Phosphatase, alkaline (84075) } \\
\text { Potassium (84132) } \\
\text { Protein, total (84155) } \\
\text { Sodium (84295) } \\
\text { Transferase, alanine amino (ALT) (SGPT) (84460) } \\
\text { Transferase, aspartate amino (AST) (SGOT) (84450) } \\
\text { Urea nitrogen (BUN) (84520) }\end{array}$ \\
\hline Liver function tests & 11.23 & Medicare clinical lab fee schedule ${ }^{30}$ & $\begin{array}{l}\text { 80076: Hepatic function panel } \\
\text { Comprises: } \\
\text { Albumin (82040) } \\
\text { Bilirubin, direct (82248) } \\
\text { Bilirubin, total (82247) } \\
\text { Phosphatase, alkaline (84075) } \\
\text { Protein, total (84155) } \\
\text { Transferase, alanine amino (ALT) (SGPT) (84460) } \\
\text { Transferase, aspartate amino (AST) (SGOT) (84450) }\end{array}$ \\
\hline Pancreatic (amylase and lipase) & 19.38 & Medicare clinical lab fee schedule ${ }^{30}$ & $\begin{array}{l}\text { 82150: Assay of amylase } \\
\text { 83690: Assay of lipase }\end{array}$ \\
\hline Coagulation & 25.99 & Medicare clinical lab fee schedule ${ }^{30}$ & $\begin{array}{l}\text { 85610: Prothrombin time } \\
\text { 85730: Thromboplastin time partial } \\
\text { 85049: Automated platelet count } \\
\text { 85002: Bleeding time test }\end{array}$ \\
\hline Urinalysis & 4.35 & Medicare clinical lab fee schedule ${ }^{30}$ & $\begin{array}{l}\text { 81000: Urinalysis, by dip stick or tablet reagent, nonauto- } \\
\text { mated, with microscopy }\end{array}$ \\
\hline ECG & 18.37 & Medicare physician fee schedule ${ }^{24}$ & 93000: Electrocardiogram complete \\
\hline Thyroid function & 56.74 & Medicare physician fee schedule 24 & 83970: Assay of parathormone \\
\hline Other & 20.16 & - & Assigned mean value for specific lab tests \\
\hline Radiological visits & 75.77 & Medicare physician fee schedule 24 & $\begin{array}{l}\text { 99214: Office E\&M visit involving decision making of } \\
\text { moderate complexity }\end{array}$ \\
\hline
\end{tabular}




\section{APPENDIX Unit Costs of Nonstudy Medical Resources in the COMPARZ Trial (continued)}

\begin{tabular}{|c|c|c|c|}
\hline Service & Cost $(\$)$ & Source $^{a}$ & Description $^{b}$ \\
\hline \multicolumn{4}{|l|}{ Radiological tests } \\
\hline CT or MRI & 179.98 & $\begin{array}{l}2013 \text { National Physician Fee } \\
\text { Schedule } 37\end{array}$ & $\begin{array}{l}\text { 74150: CT scan of abdomen without contrast material } \\
\text { Work RVU: } 1.19 \text {, facility practice expenses RVU: } 4.02 \text {, mal- } \\
\text { practice expenditures RVU: } 08 \text {, Conversion factor: } 34.023\end{array}$ \\
\hline DCE MRI & 461.35 & $\begin{array}{l}2013 \text { National Physician Fee } \\
\text { Schedule } 37\end{array}$ & 76390: Magnetic resonance spectroscopy \\
\hline PET scan & $1,056.12$ & $\begin{array}{l}\text { GE Healthcare Reimbursement for } \\
\text { PET } 201331\end{array}$ & $\begin{array}{l}\text { 78811: Tumor imaging, positron emission tomography } \\
\text { (PET); limited area (e.g., chest, head/neck) }\end{array}$ \\
\hline PET/CT scan & $1,056.12$ & $\begin{array}{l}\text { GE Healthcare Reimbursement for } \\
\text { PET } 2013^{31}\end{array}$ & $\begin{array}{l}\text { 78811: Tumor imaging, positron emission tomography } \\
\text { (PET); limited area (e.g., chest, head/neck) }\end{array}$ \\
\hline Bone scan & 108.19 & Medicare physician fee schedule 24 & 77075: X-rays, bone survey, complete \\
\hline Other & 261.00 & - & Assigned mean value for specific radiological tests \\
\hline Home health visits & 78.59 & Medicare physician fee schedule 24 & $\begin{array}{l}\text { 99325: Domiciliary/rest home visit; new patient, presenting } \\
\text { problems of moderate severity }\end{array}$ \\
\hline \multicolumn{4}{|c|}{ Hospital days (hospitalization at least 24 hours) } \\
\hline General ward & $2,406.18$ & $\begin{array}{l}\text { National statistics on all stays from } \\
\text { HCUPnet; } 27 \text { Calculation; Medicare } \\
\text { physician fee schedule } 24\end{array}$ & $\begin{array}{l}\text { ICD-9-CM code: 189.0-Malignant neoplasm: Kidney, } \\
\text { except pelvis } \\
\text { Kidney not otherwise specified } \\
\text { Kidney parenchyma } \\
\text { 99232: Subsequent hospital care, per day, for E\&M of } \\
\text { patient involving decision making of moderate complexity }\end{array}$ \\
\hline ICU & $4,672.95$ & Halpern and Pastores, $2010^{28}$ & $\begin{array}{l}\$ 3,518 \text { in } 2005 \text { USD inflated to } 2013 \text { USD using medical } \\
\text { care Consumer Price Index from Bureau of Labor Statistics }\end{array}$ \\
\hline Emergency room visits & 222.76 & Bamezai et al., $2005^{29}$ & - \\
\hline \multicolumn{4}{|l|}{ Medical/surgical procedures } \\
\hline At outpatient/physician clinic & 0.00 & - & $\begin{array}{l}\text { The costs of medical/surgical procedures were assumed to } \\
\text { be included in the costs of outpatient visits and hospital- } \\
\text { izations }\end{array}$ \\
\hline During any hospitalization & 0.00 & - & $\begin{array}{l}\text { The costs of medical/surgical procedures were assumed to } \\
\text { be included in the costs of outpatient visits and hospital- } \\
\text { izations }\end{array}$ \\
\hline \multicolumn{4}{|c|}{$\begin{array}{l}{ }^{a} \text { Citations for these sources are found in the References listed at the end of this article. } \\
\text { bUnless otherwise indicated, } C P T \text { codes are used in this column. } \\
\text { BUN=blood urea nitrogen; } C B C=\text { complete blood count; } C P T=C \text { Current Procedural Terminology; } C T=\text { computed tomography; DCE MRI=dynamic contrast-enhanced } \\
\text { magnetic resonance imaging; EEM = evaluation and management; } E C G=\text { electrocardiogram; ICD-9-CM=International Classification of Diseases, Ninth Revision, Clinical } \\
\text { Modification; ICU = intensive care unit; } R V U=\text { relative value unit; } S G O T=\text { serum glutamic oxaloacetic transaminase; SGPT = serum glutamic pyruvic transaminase; } \\
\text { USD =U.S. dollars; } W B C=\text { whole blood count. }\end{array}$} \\
\hline
\end{tabular}

